\title{
AURIS KEYBOARD: FERRAMENTA DE AUXÍLIO AO TREINAMENTO DE PERCEPÇÃO MUSICAL PARA PESSOAS SURDAS
}

\author{
Auris Keyboard: aid tool for training musical \\ perception for deaf people
}

\author{
Auris Keyboard: herramienta de ayuda para \\ la formación de la percepción musical para \\ personas sordas
}

CAIO VinícIus PEREIRA de SÁ Universidade Federal da Paraíba caiovpsa@yahoo.com.br

\author{
CARlos Eduardo CoElho Freire Batista \\ Universidade Federal da Paraíba \\ ebidu@ci.ufpb.br
}

\author{
DONATELY DA COSTA SANTOS \\ Chronos Escola de Música \\ donately.costa@gmail.com
}

\begin{abstract}
Resumo: A presente pesquisa trata do processo de inclusão de indivíduos surdos ao ensino formal de música, por meio da tradução da informação sonora em vibração tátil. A partir da compreensão das ferramentas e metodologias já utilizadas para dar suporte ao ensino de música para pessoas surdas, foi possivel o desenvolvimento de uma nova ferramenta contendo algumas das principais características exitosas nos estudos anteriores. Realizou-se, então, uma pesquisa quantitativa, com base em experimentos realizados com grupos de indivíduos surdos e ouvintes, que utilizaram o protótipo construído, e geraram informações para sustentar uma análise da capacidade da percepção tátil de elementos rítmicos e melódicos. O uso da ferramenta foi avaliado como positivo para os casos abordados, o que sugere que a tradução do som para vibrações táteis é possivel e pode ser utilizada para atividades relacionadas ao ensino formal de música.
\end{abstract}

Palavras-chave: Educação Musical. Acessibilidade. Música para surdos.

Abstract: The present research deals with the process of inclusion of deaf individuals to the formal teaching of music, through the translation of sound information into tactile vibration. From the understanding of the tools and methodologies already used to support the teaching of music for deaf people, it was possible to develop a new tool containing some of the main successful characteristics in previous studies. A quantitative research was then carried out, based on experiments with groups of deaf individuals and listeners, who used the built prototype, and generated information to support an analysis of the capacity of the tactile perception of rhythmic and melodic elements. The use of the tool was evaluated as positive for the cases addressed, suggesting that the translation of sound to tactile vibrations is possible and can be used for activities related to the formal teaching of music.

Keywords: Music Education. Accessibility. Music for the Deaf.

Resumen: Esta investigación aborda el proceso de inclusión de personas sordas en la enseñanza formal de la música a través de la traducción de información sonora en vibración táctil. A partir de la comprensión de las herramientas y metodologías ya utilizadas para apoyar la enseñanza de la música a personas sordas, fue posible desarrollar una nueva herramienta que contenía algunas de las principales características exitosas de estudios anteriores. Luego, se realizó una investigación cuantitativa, basada en experimentos realizados con grupos de personas sordas y oyentes que utilizaron el prototipo construido y generaron información para respaldar un análisis de la capacidad de percepción táctil de elementos rítmicos y melódicos. El uso de la herramienta se evaluó como positivo para los casos abordados, lo que sugiere que la traducción del sonido a las vibraciones táctiles es posible y puede utilizarse para actividades relacionadas con la educación musical formal.

Palabras clave: Educación musical. Accesibilidad. Música para sordos. 


\section{INTRODUÇÃO}

Segundo informações disponibilizadas no site do governo federal brasileiro ${ }^{1}$, de acordo com o Censo de $2010^{2}$, realizado pelo Instituto Brasileiro de Geografia e Estatística (IBGE), 9,7 milhões de pessoas possuem algum grau de deficiência auditiva no Brasil. Dessas, mais de 2 milhões apresentam deficiência auditiva severa, situação em que há uma perda da capacidade auditiva para a faixa entre 70 e 90 decibéis (dB), e quase metade desses afetados por surdez severa é composta por jovens de até 19 anos. De acordo com informações do Censo de 2005 do Ministério da Educação, existiam mais de 66 mil alunos surdos matriculados da educação infantil ao ensino médio, o que representa $0,12 \%$ do total de matriculados (Finck, 2009).

Buscando contribuir com a diminuição da demanda gerada por tais números, foram criadas as Classes Inclusivas - nestas classes, as escolas recebem alunos com necessidades especiais e desenvolvem atividades didáticas diversas com uma agenda de inclusão social. Crespo define a escola inclusiva da seguinte maneira: "A Escola Inclusiva respeita e valoriza todos os alunos, cada um com a sua característica individual, e é a base da Sociedade para Todos, que acolhe todos os cidadãos e se modifica, para garantir que os direitos de todos sejam respeitados" (Crespo, 2005, p.14). Dentro da perspectiva demonstrada, as classes inclusivas abrangem as diversas áreas do conhecimento de forma lúdica, fazendo com que os indivíduos não sejam excluídos da possibilidade de aprendizagem.

Uma das atividades desenvolvidas nas escolas de educação básica é o ensino de música, retornando ao currículo após o decreto e sanção da Lei $\mathrm{n}^{\circ}$ $11.769 / 2008^{3}$, que alterou a Lei de Diretrizes e Bases da Educação, restabelecendo este ensino como obrigatório. Como atividade artística presente nas escolas, a música desenvolve estímulos perceptivos e, geralmente, cria ambientes de interação social. Para Gainza (1988), a música é um elemento de fundamental importância, pois movimenta, mobiliza e por isso contribui para a transformação e o desenvolvimento. A música não substitui o restante da educação, ela tem como função atingir o ser humano em sua totalidade.

Mesmo com a implantação do ensino de música nas escolas, as aulas de música para alunos surdos encontram algumas dificuldades, que vão além da restrição física do aluno. Em sua pesquisa, Cruz (1997) relata que

\footnotetext{
1 Disponível em: http://www.brasil.gov.br/cidadania-e-justica/2016/09/apesar-de-avancos-surdos-aindaenfrentam-barreiras-de-acessibilidade.

${ }^{2}$ Até o presente momento não houve novas pesquisas para atualização dos dados.

3 BRASIL. Lei no 11.769, de 18 de agosto de 2008. Altera a Lei no 9.394, de 20 de dezembro de 1996, Lei de Diretrizes e Bases da Educação, para dispor sobre a obrigatoriedade do ensino da música na educação básica. Brasília, 2008. Disponível em: http://www.planalto.gov.br/ccivil_03/_ato2007-2010/2008/lei/l11769.htm.
} 
os problemas podem ser de ordem estrutural, quando não há espaços adaptados e equipamentos adequados, ou de ordem conceitual, quando há despreparo por parte dos professores ou mesmo por desinteresse de alguns alunos.

Com o avanço e acessibilidade das ferramentas de auxílio aos métodos de ensino, surgiu o questionamento que norteou esta pesquisa: De que modo uma ferramenta tecnológica pode auxiliar o ensino formal de música para a comunidade surda? Para discutir tal questionamento, há a necessidade de conhecimentos interdisciplinares em música, computação e fisiologia, tornando possivel a elaboração de hipóteses a serem testadas através de experimentação.

O trabalho tem como objetivo geral auxiliar a acessibilidade dos surdos ao ensino formal de música, propondo formas de representação do som para esta comunidade e buscando promover a inclusão dos mesmos em turmas regulares.

Para que tal objetivo, citado anteriormente, seja alcançado, se faz necessária a realização de alguns procedimentos, especificados da seguinte maneira:

$\checkmark$ Compreender as ferramentas e metodologias utilizadas para o suporte ao ensino de música para pessoas surdas;

$\checkmark$ Analisar as possibilidades da relação entre a percepção auditiva e a percepção tátil para o ensino formal de música para pessoas surdas;

$\checkmark$ Construir uma ferramenta de acessibilidade ao ensino de música para indivíduos surdos.

Os objetivos descritos justificam-se pela atual situação do panorama de acessibilidade para surdos e a necessidade de implementar novas ferramentas que possam auxiliar o ensino dos mesmos.

\section{A EDUCAÇÃO MUSICAL E OS SURDOS}

Os arquivos de pesquisas e documentações disponíveis, graças às contribuições de antropólogos e musicólogos, deixam claro que a música faz parte da aprendizagem e do ensino desde tempos remotos. Estudiosos de sociedades pré-letradas afirmam que não existem grupos humanos desprovidos de música, ainda que sob formas rudimentares. Graças às contribuições da etnomusicologia, que contam com livros e publicações de periódicos especializados, vêm sendo desvendados esses primórdios da música e do ensino musical em povos que não contam com registros escritos (Bréscia, 2003).

Já o ensino formal de música é uma atividade que pode ser observada em propostas citadas por Platão na antiguidade clássica, a qual fazia parte do currículo básico das crianças e jovens, juntamente com ginástica e gramática (Grout; Palisca, 2007). Além de criar um desenvolvimento 
artístico, desenvolve a sensibilidade e a percepção do indivíduo de forma que o mesmo entenda as suas qualidades artísticas junto a outras pessoas de distintas culturas.

Evidentemente o ensino de música só pode ter êxito se transformado em uma ação significativa, o que pressupõe uma permanente abertura para o novo num diálogo permanente com a realidade sociocultural dos alunos. Neste contexto é onde se desenvolvem as metodologias para educação musical, a fim de obter os melhores resultados de aprendizado por parte dos alunos.

O primeiro trabalho com surdos, registrado em periódicos, foi uma pesquisa de Karl Wecker, publicada em 1 de maio de 1938. Intitulado "Music for totally deaf children", Wecker (1938) utilizou aparatos tecnológicos para os experimentos. Um grupo de crianças surdas foi submetido a sons musicais amplificados e enviados para headphones individuais. Os primeiros sons eram voltados para a percepção rítmica dos indivíduos, sugerindo a sinalização quando houvesse mudanças perceptiveis aos mesmos. A segunda parte da pesquisa, e mais surpreendente, continha mudanças de frequências no som emitido, onde alguns indivíduos não só reconheceram a mudança, como cantaram a nota sugerida. Esta pesquisa demonstrou que a percepção tátil não só é eficaz como também pode atingir diferentes estruturas cerebrais.

Em 1972, a pesquisa de Joan Dahms Fahey e Lois Birkenshaw, chamada "Education of the deaf bypassing the ear: the perception of music by feeling and touch", relata uma análise da metodologia utilizada em uma sala de aula com crianças surdas. O instrumento utilizado para os exercícios de percepção tátil foi o piano. Os exercícios eram realizados em graus de dificuldade. No primeiro nivel, as crianças colocam suas mãos sobre o piano e indicam o momento em que o som para de soar. No segundo nível, elas devem andar em volta do piano e indicar o momento em que o mesmo para de tocar. No terceiro nivel, as crianças voltam a colocar suas mãos sobre o piano e fazem testes de reconhecimento de frequência, verificando se o som é grave ou agudo (Fahey; Birkenshaw, 1972). A pesquisa demonstrou que a percepção tátil dos indivíduos envolvidos foi capaz de reconhecer padrões sonoros por meio das vibrações que atingiam as diferentes partes dos seus corpos.

Em 1985, Alice-Ann Darrow publica Music for deaf, onde demonstra a importância do ensino de música para surdos, a interação e a inclusão que as classes musicais provocam no indivíduo. A pesquisa relata a utilização de instrumentos percussivos (tambores, pratos, sinos cromáticos) que fazem com que os alunos, mesmo com surdez profunda, consigam sentir as vibrações das ondas sonoras, permitindo distinguir as variáveis de intensidade e a duração dos sons. A autora defende que os estímulos causados pela inclusão dos indivíduos surdos nas aulas coletivas de música 
podem ser tão satisfatórios quanto para os indivíduos ouvintes (Darrow, 1985).

Em 2009, Regina Finck se propôs a "investigar como se dá o processo de aprendizagem musical de alunos surdos no contexto inclusivo, com vistas a sistematizar uma base para educação musical com esses alunos junto à escola regular, mais precisamente no município de Florianópolis/SC" (Finck, 2009, p.8). Esta pesquisa chama a atenção pela sua preocupação em sistematizar um plano metodológico para a educação musical com a finalidade de ser utilizada em espaços de inclusão, por meio da criação e utilização de materiais pedagógicos adaptados a este contexto. Foi constatado que, a partir da criação e da utilização de materiais adaptados e de recursos pedagógicos, foi possivel notar aprendizagens musicais significativas, o que comprova a possibilidade da estruturação de elementos de ação musical direcionados a crianças surdas.

Em 2018, o docente Magnaldo Araújo, do Instituto Federal do Rio Grande do Norte, desenvolveu uma ferramenta que tem por finalidade orientar, por meio de uma linguagem visual de sinais luminosos, como executar células rítmicas presentes em músicas e exercícios musicais, chamado MagMusic ${ }^{4}$. O aparelho emite sinais luminosos que simulam pulsações rítmicas ajustadas por batidas por minuto (BPM), similar a um metrônomo ${ }^{5}$, onde cada lâmpada do aparelho tem uma função acionada pelo microcontrolador, de acordo com a configuração inserida pelo usuário. A ferramenta ainda possui um visor que pode indicar cifras de acordes, no qual o usuário pode se nortear para sua interpretação em instrumentos harmônicos. Esta invenção tem sido desenvolvida para operação na área de Arte para ajudar pessoas com deficiência auditiva a aprenderem música.

Nota-se que, na maioria dos experimentos, os métodos ativos de ensino são, de alguma forma, modificados para que atendam à necessidade dos alunos surdos. O uso de aparatos tecnológicos, disponíveis em cada época, também auxiliou os pesquisadores a desenvolverem os métodos. Pode-se concluir também que, apesar das diversas formas aplicadas pelos educadores, a vibração é um dos estímulos mais comumente empregados para treinamento de habilidades que envolvem trabalho com pessoas surdas e vem sendo amplamente aplicado no contexto do ensino de música e dança para esse público, tendo gerado um corpo robusto de pesquisas dedicadas ao método e a produção de diversas tecnologias assistivas, a maioria consistindo em dispositivos vibrotáteis.

\footnotetext{
${ }^{4}$ SILVA, Anna Paullina. Magmusic: invenção de professor do Campus Apodi é aprovado para a Campus Party. Instituto Federal - Rio Grande do Norte, 21 mar. 2018. Disponível em: http://portal.ifrn.edu.br/campus/reitoria/noticias/magmusic-invencao-de-professor-do-campus-apodi-eaprovado-para-a-campus-party.

${ }^{5}$ Aparelho que, através de pulsos (sonoros ou luminosos) de duração regular, indica um andamento musical.
} 


\section{MATERIAIS E MÉTODOS DE PESQUISA}

O presente trabalho, de natureza aplicada, norteou-se pelo método quantitativo, a fim de validar a eficácia da ferramenta desenvolvida perante os indivíduos voluntários e a visão dos mesmos sobre o tema. Segundo Richardson (1999), a pesquisa quantitativa é caracterizada pelo emprego da quantificação, tanto nas modalidades de coleta de dados quanto no tratamento delas por meio de técnicas estatísticas. O uso da descrição quantitativa apresenta melhor compreensão e dinamiza o processo de relação entre variáveis.

Esta pesquisa se caracteriza como de natureza exploratória. Segundo Malhotra (2001), este tipo de pesquisa é utilizado em casos nos quais é necessário definir o problema com maior precisão, suas constatações são experimentais, e o resultado, geralmente, seguido por outras pesquisas exploratórias ou conclusivas (Malhotra, 2001).

Quanto ao procedimento, devido ao desenvolvimento de uma de ferramenta, foi utilizado o modelo de pesquisa experimental, a fim de coletar os dados sobre seu desempenho com os indivíduos participantes. Neste caso, a análise foi feita acerca da percepção tátil em três tipos de indivíduos: surdos, ouvintes sem treinamento auditivo e ouvintes com treinamento auditivo. De acordo com Gil (2007), a pesquisa experimental consiste em determinar um objeto de estudo, selecionar as variáveis que seriam capazes de influenciá-lo, definir as formas de controle e de observação dos efeitos que a variável produz no objeto.

A coleta de dados do experimento foi feita por meio de questionários estruturados, com perguntas abertas e/ou fechadas. Segundo Cervo e Bervian (2002), o questionário refere-se a um meio de obter respostas às questões por uma fórmula que o próprio informante preenche.

\section{Experimentos}

Os experimentos com o protótipo foram realizados em uma única sessão com cada um dos indivíduos voluntários. Na oportunidade lhes foram expostas as finalidades e as funções da ferramenta e sua relação com os elementos rítmicos e melódicos da música. Para os voluntários que não possuíam conhecimento musical (ouvintes e surdos), uma breve explanação sobre os conceitos da física do som e notas musicais lhes foi apresentada, a fim de lhes situar da relação que há entre as ondas sonoras e as vibrações táteis.

Os exercícios foram propostos com duas finalidades de interpretação para os indivíduos: a) Diferenciação de frequências de vibração, com pares de notas próximas e distantes. Para os ouvintes músicos, também foi acrescentado o quesito de identificação de notas, apenas pelas vibrações; b) identificação de variações rítmicas. 


\section{Perfil dos voluntários}

Os experimentos foram realizados com dois grupos distintos de voluntários com idades entre 19 e 48 anos. O primeiro grupo, formado por ouvintes, contou com a participação de 7 pessoas: 2 homens e 5 mulheres. Neste grupo houve uma subdivisão, contendo 3 ouvintes músicos (com treinamento auditivo) e 4 ouvintes sem treinamento. $O$ segundo grupo, formado por individuos surdos, continha 7 pessoas, sendo 4 mulheres e 3 homens. Neste, também houve subdivisão entre os individuos, contendo 2 surdos com contato prévio com educação musical e 5 que não tiveram contato algum anteriormente. Esta amostragem de indivíduos justifica-se por se tratar de uma validação a respeito das funcionalidades de uma ferramenta desenvolvida e se estas funcionalidades podem ser representadas de forma eficaz para pessoas surdas. A presença dos indivíduos ouvintes, músicos ou não, na pesquisa foi imprescindivel para validar a possibilidade da relação entre as frequências da percepção tátil e da percepção sonora.

Um questionário foi aplicado a cada membro dos grupos de voluntários. O questionário aplicado aos indivíduos músicos apresentava algumas questões com abordagem diferente do questionário aplicado aos indivíduos surdos e aos ouvintes sem treinamento. Neste, além de questões objetivas, o individuo teria que transcrever trechos com parâmetros rítmicos e identificar frequências e padrões melódicos através da percepção tátil. Deste modo, seria possivel avaliar a possibilidade da correlação entre a percepção tátil e a percepção sonora.

\section{INSTRUMENTOS DE PESQUISA}

A ferramenta Auris Keyboard foi elaborada a fim de promover uma experiência de sensação sonora para surdos, tendo como objetivo o auxílio ao ensino musical destes indivíduos. O protótipo, desenvolvido para os experimentos, utilizou uma plataforma de prototipagem chamada Arduino, modelo que utiliza o chip Atmega328. O software utilizado para realizar o conjunto de instruções empregadas foi o Arduino 1.6.6, em sua versão para o sistema operacional Windows. Para a reprodução das vibrações, foi utilizado um motor vibracall de 5 volts, comumente utilizado nos celulares atualmente. Também foi projetado um teclado com doze botões de acionamento para o motor, do tipo chave táctil, cada um com uma respectiva nota. A disposição dos elementos que compõem a ferramenta é descrita da seguinte forma: 


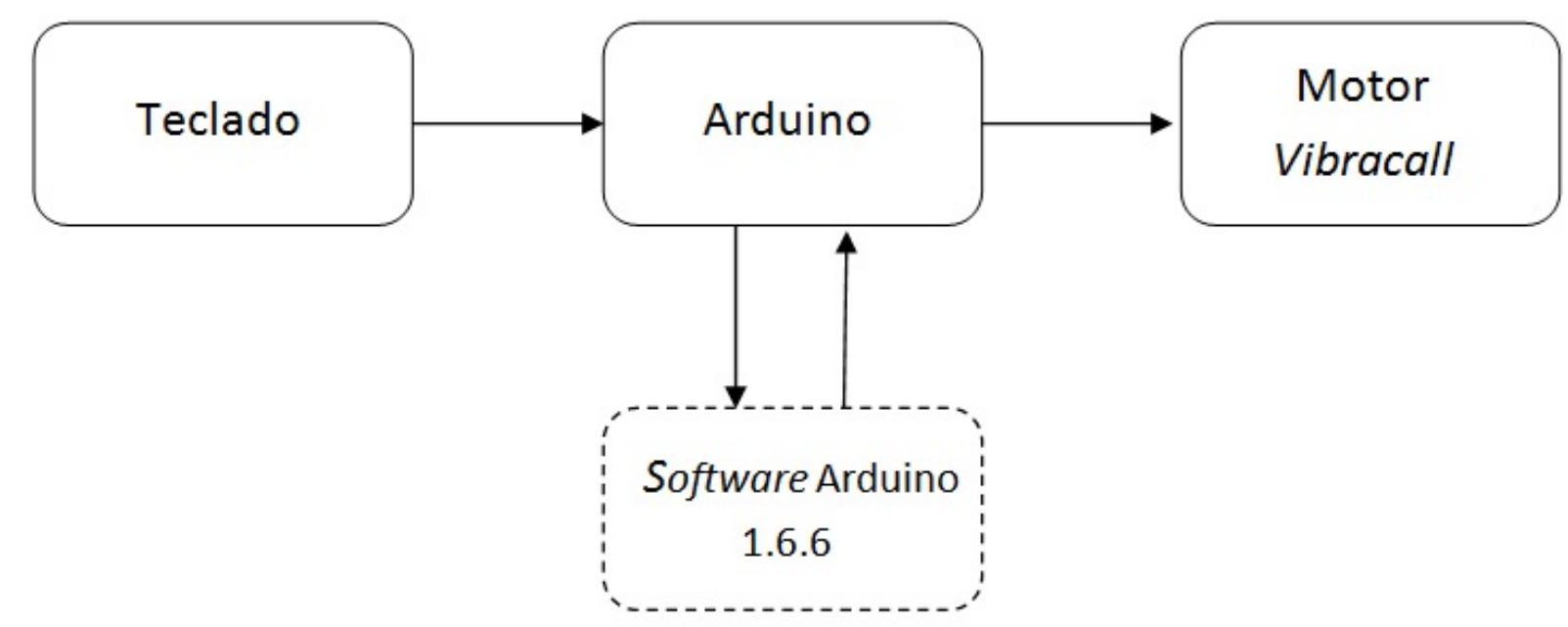

Figura 1: Arquitetura da Auris Keyboard. Fonte: Elaboração própria.

Podemos observar que o hardware é formado basicamente por três partes - teclado, Arduino e motor vibracall -, as quais são interligadas e coordenadas por um software.

O detalhamento da arquitetura da ferramenta pode ser demonstrado no esquema de montagem a seguir.

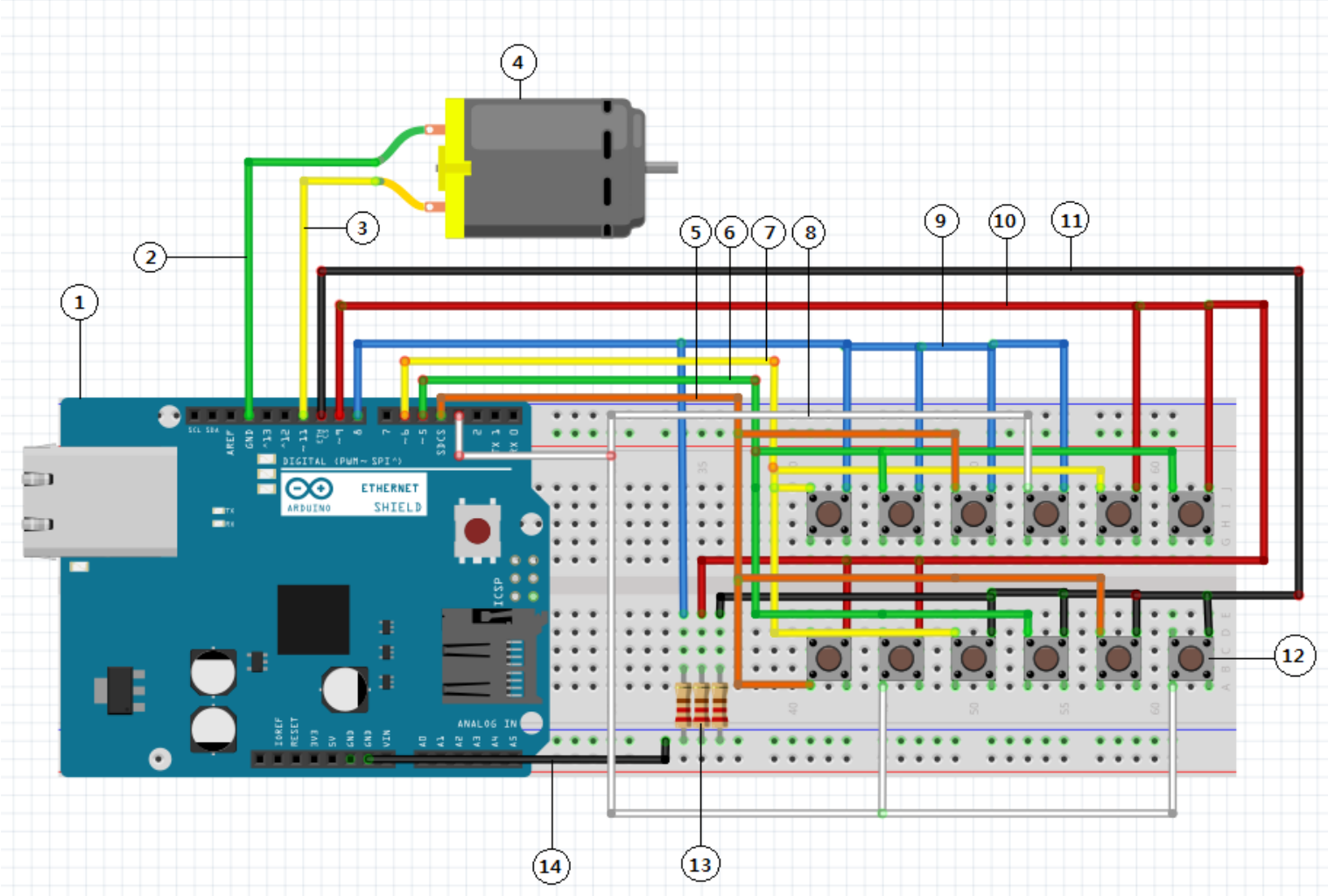

Figura 2: Esquema de montagem da ferramenta. Fonte: Elaboração própria. 
A placa de Arduino (1) permite que se controlem os aspectos elétricos de seus pinos, seja entrada ou saída de sinal. Através do pino 11 (3), o motor vibracall (4) recebe o sinal do Arduino, reproduzindo uma frequência predefinida. Por meio do pino $\operatorname{GND}^{6}$ (2) acontece o retorno para a placa, completando o circuito do motor. Os botões de acionamento do teclado (12) funcionam como um interruptor, que, ao receber alimentação de $5 \mathrm{~V}$ dos pinos $(5,6,7,8)$, se acionados, fazem com que a corrente elétrica chegue aos pinos de entrada $(9,10,11)$ os quais serão direcionados para o motor. Como os grupos de notas foram divididos em três partes, de acordo com a latência de acionamento, cada grupo de notas é direcionado para um resistor (13) diferente, a fim de realizar o controle de potência do motor por meio da $\mathrm{PWM}^{7}$. Este tipo de controle consegue alternar o estado do pino de saída entre 0 e 5 volts, controlando alternância de estados (ligado desligado), fazendo o motor girar mais rápido ou mais devagar. O retorno para este grupo de acionamento é feito pelo segundo pino GND (14), completando o circuito.

O funcionamento lógico da ferramenta pode ser descrito da seguinte forma:

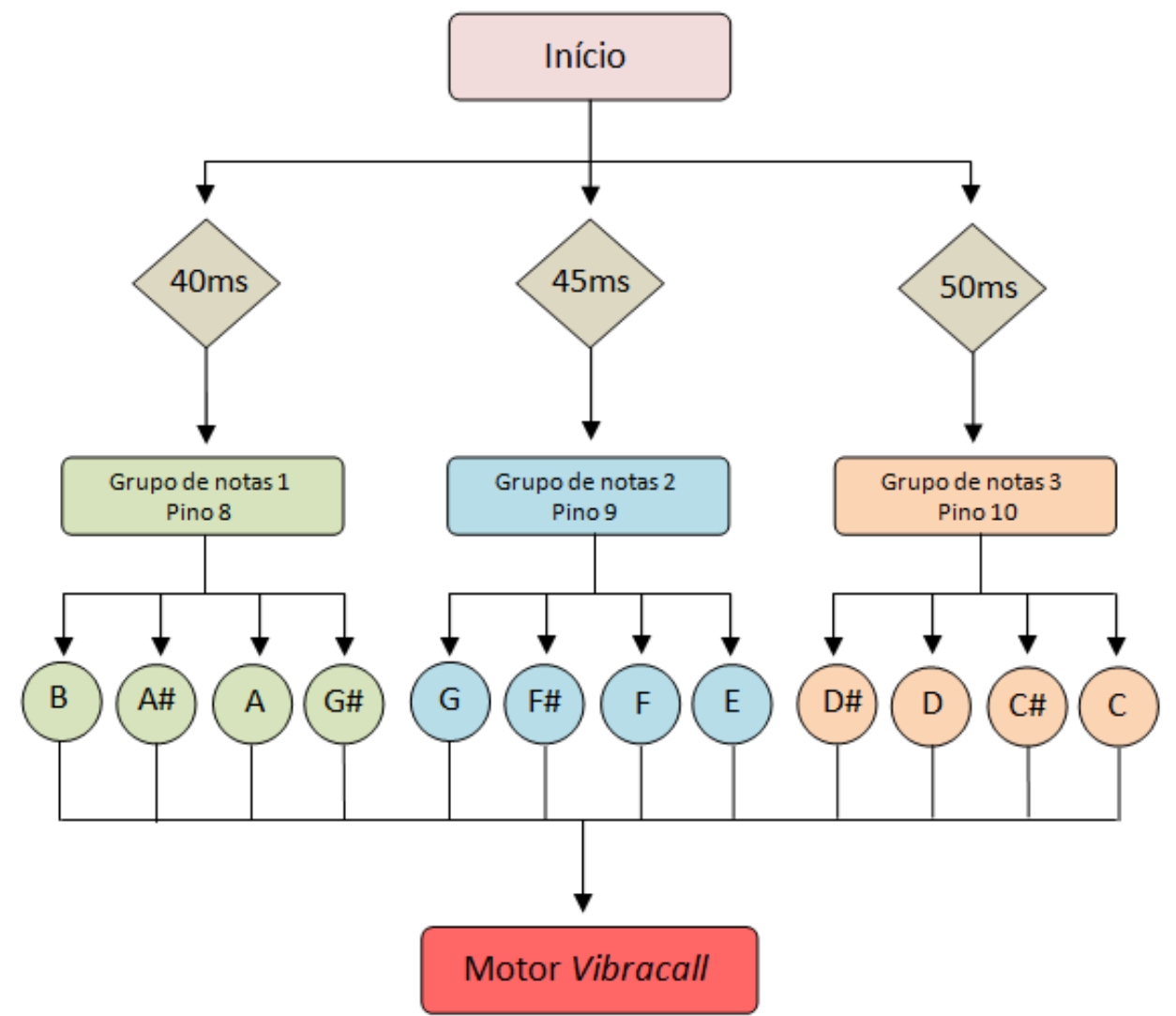

Figura 3: Fluxograma de funcionamento da ferramenta. Fonte: Elaboração própria.

\footnotetext{
${ }^{6}$ Graduated neutral density filter (filtro graduado de densidade neutra)

${ }^{7}$ Pulse Width Modulation (Modulação de Largura de Pulso)
} 
A Figura 3 demonstra que, no princípio, o programa ajusta os pinos do chip para que sejam saídas e entradas. Logo em seguida inicia o monitor de saida serial (apenas quando ligado a um computador). Em seguida, um loop (parte do programa que se repete continuamente) que funciona da seguinte maneira:

$\checkmark$ Um contador (ti), que vai apenas de 3 a 6 . é iniciado e, em seguida, os pinos $3(8), 4(5), 5(6)$ e 6 (7) recebem 0 volts e assim são DESLIGADOS.

$\checkmark$ O pino que tem o mesmo número do contador é então LIGADO, ou seja, recebe 5 volts (na primeira vez que o programa roda, o contador está no número 3).

$\checkmark$ O programa testa a recepção do pino 8 (9), confirmando se está LIGADO e em qual dos pinos.

$\checkmark$ Se o sinal for recebido, ele ajusta a saida para o valor do PWM referente à nota, mas não o coloca no motor ainda.

$\checkmark$ Liga o motor no seu valor máximo por 40 milissegundos, tempo necessário para forçar a resposta do motor (com notas mais graves, o tempo tem que ser um pouco maior).

$\checkmark$ Enquanto o sinal LIGADO estiver sendo lido, ele coloca no motor um valor ajustado para a saida. Assim que o sinal deixa de ser lido, ele coloca 0 (zero) no motor, desligando-o.

$\checkmark$ O programa testa o próximo pino 9 (10), refazendo os passos anteriores.

$\checkmark$ O programa testa o próximo pino 10 (11), refazendo os passos anteriores.

$\checkmark$ Ao final dos testes, o programa aguarda 10 milissegundos e recomeça o loop.

$\checkmark$ Quando o loop recomeça, o contador é adicionado de 1, e com o valor 4 refaz todo o programa, também com o 5 e com o 6 .

O teclado (Figura 4) foi configurado de modo que as doze notas estivessem dispostas em ordem ascendente, facilitando o manuseio para o músico/pesquisador ${ }^{8}$. Ao acionar a nota desejada, um sinal é enviado para o Arduino, o qual interpreta a duração e a frequência que o motor vibracall deve operar (Figura 5). A disposição da ferramenta pode ser visualizada a seguir:

\footnotetext{
${ }^{8}$ AURIS Keybord. [S. I.: s. n.], 2019. 1 vídeo (1min27seg). Publicado pelo canal Caio de Sá. Disponível em: https://www.youtube.com/watch?v=W9y0Z6it44A\&feature=youtu.be.
} 


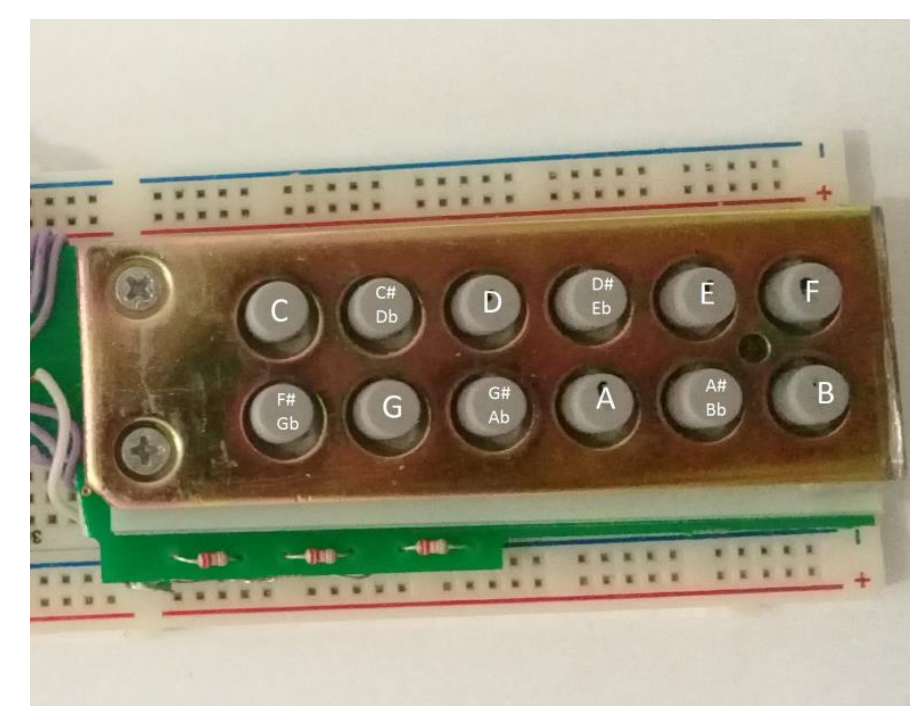

Figura 4: Teclado controlador. Fonte: Elaboração própria.

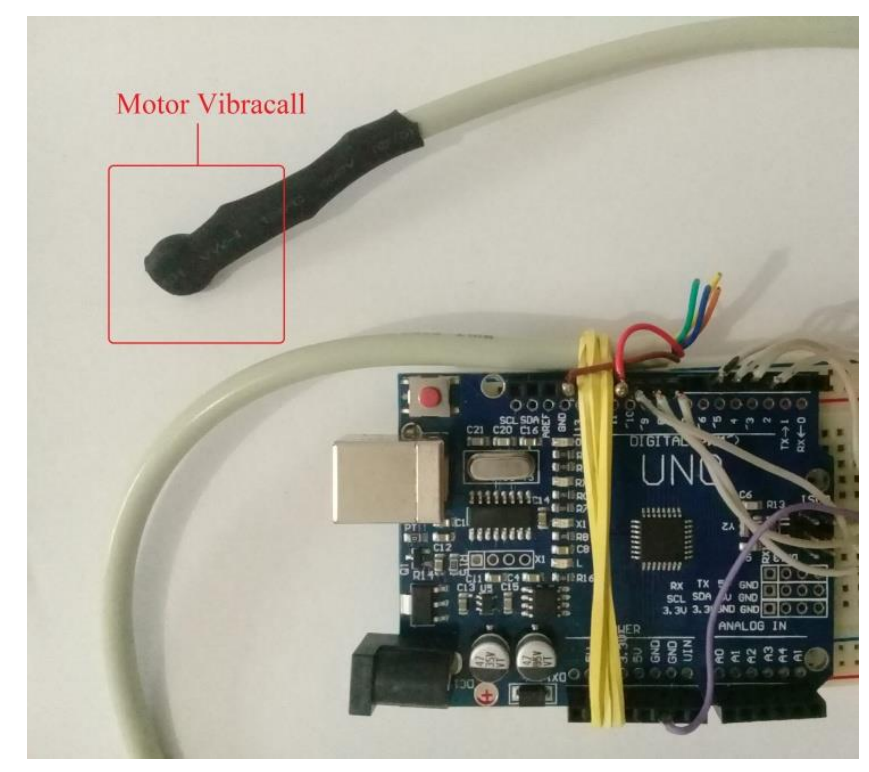

Figura 5: Arduino e motor vibracall. Fonte: Elaboração própria.

A relação entre vibração e frequência sonora foi realizada através da conversão de unidades de medida. Motores têm como unidade de medida de funcionamento o $\mathrm{rpm}$ (rotações por minuto), considerando uma rotação como um ciclo completo de onda. As alturas do som, por sua vez, são medidas por ciclos por segundo $\mathrm{Hz}$, como citado anteriormente. Para que se torne audivel ao ser humano, é necessário que as ondas possuam entre 20 $\mathrm{Hz}$ a $20.000 \mathrm{~Hz}$. Deste modo, para que haja a conversão de uma unidade para outra, podemos considerar que $1 \mathrm{~Hz}=60 \mathrm{rpm}$, sendo assim, um motor só pode ser compreendido, pelo ser humano, com uma frequência sonora a partir de $1.200 \mathrm{rpm}$.

Considerando a característica das parciais harmônicas das ondas sonoras, onde a frequência fundamental pode ter múltiplos exatos, gerando notas mais agudas ou graves (por ex., Lá: 440 Hz; Lá: 880 Hz; Lá: 1.760 Hz), 
podemos obter a relação das unidades, dividindo as frequências em $\mathrm{Hz}$ até um ponto equivalente em rpm, onde o motor possa suportar os ciclos.

O motor vibracall utilizado no experimento possui capacidade máxima de $9.000 \mathrm{rpm}$, a qual pode variar dependendo do modelo ou fabricante. Desta forma, uma conversão de unidades foi realizada para que o motor comportasse uma série de notas necessárias para a pesquisa, gerando a seguinte Tabela 1, abaixo:

\begin{tabular}{|c|c|c|c|}
\hline Nota & $\mathbf{H z}$ & rpm & $\begin{array}{l}\text { Capacidade de } \\
\text { rotação do motor }\end{array}$ \\
\hline $\mathbf{C}$ & 66 & 3.960 & $44 \%$ \\
\hline $\mathbf{C \# / D b}$ & 69.8 & 4.008 & $45 \%$ \\
\hline D & 74 & 4.440 & $49 \%$ \\
\hline D\# / Eb & 78,4 & 4.704 & $52 \%$ \\
\hline $\mathbf{E}$ & 83,1 & 4.986 & $55 \%$ \\
\hline $\mathbf{F}$ & 88,1 & 5.286 & $59 \%$ \\
\hline $\mathbf{F} \# / \mathbf{G b}$ & 93,3 & 5.598 & $62 \%$ \\
\hline $\mathbf{G}$ & 98,8 & 5.928 & $65 \%$ \\
\hline $\mathbf{G \# / \mathbf { A b }}$ & 104,7 & 6.282 & $70 \%$ \\
\hline $\mathbf{A}$ & 111 & 6.660 & $74 \%$ \\
\hline A\# & 117,6 & 7.056 & $79 \%$ \\
\hline $\mathbf{B}$ & 124,6 & 7.476 & $83 \%$ \\
\hline
\end{tabular}

Tabela 1: Conversão de unidades. Fonte: Elaboração própria.

A Tabela 1 representa as sete notas musicais $(\mathrm{C}=\mathrm{Dó} ; \mathrm{D}=\mathrm{Ré} ; \mathrm{E}=\mathrm{Mi} ; \mathrm{F}$ = Fá; $\mathrm{G}=\mathrm{Sol} ; \mathrm{A}=\mathrm{Lá} ; \mathrm{B}=\mathrm{Si}$ ), incluindo os semitons ${ }^{9}$ existentes entre elas, que são representados pelos símbolos \# (sustenido) e b (bemol).

Nota-se que o motor necessita de um tempo de resposta para atingir a porcentagem indicada, devido ao processamento da informação. Para as notas, C - C\# - D - D\#, o tempo de resposta foi de 50 milissegundos; para as notas, E - F - F\# - G, o tempo de resposta foi de 45 milissegundos, e, para as notas, G\# - A - A\# - B, o tempo foi de 40 milissegundos. Apesar de haver uma distância temporal para o acionamento, por ser muito pequena, tornase quase imperceptivel para o indivíduo.

Durante os experimentos, a ferramenta foi apresentada previamente aos indivíduos, os quais puderam sentir todas as vibrações das doze notas, de maneira ascendente (com o aumento de frequências de vibrações) e de maneira descendente (com a diminuição das frequências). A demonstração se deu da seguinte forma:

\footnotetext{
${ }^{9}$ Semitom é considerado menor intervalo audível para a música ocidental
} 


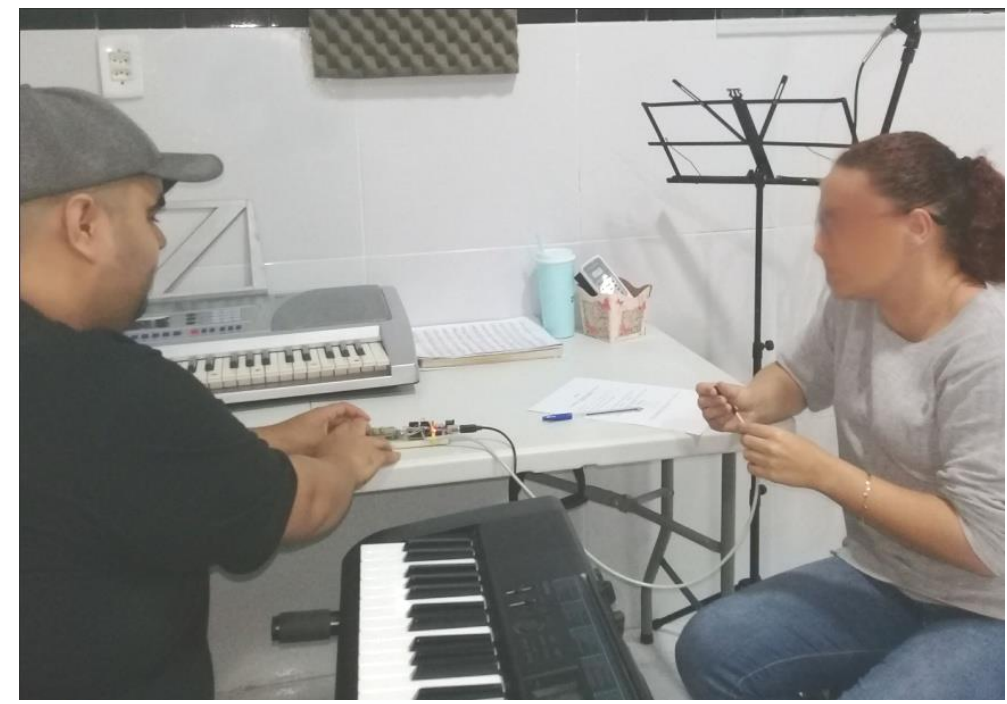

Figura 5: Teste com voluntário. Fonte: Elaboração própria.

Posteriormente o teclado da ferramenta foi posto fora do campo de visão dos voluntários, não sendo possivel que os mesmos pudessem observar se haveria mudança na digitação das notas.

\section{Os testes com surdos e ouvintes não músicos}

Nesta etapa os exercícios foram conduzidos a fim de testar a capacidade de percepção dos indivíduos a respeito da diferença entre vibrações e acerca do ritmo, sem levar em consideração a nomenclatura das notas musicais, visto que grande parte deles não as conhecia. A experiência de percepção dos mesmos foi avaliada por meio de questionários contendo questões objetivas e questões práticas, estas últimas relacionadas à interpretação de ritmo e melodias.

No primeiro exercício, foram apresentados pares de vibrações nos quais os voluntários deveriam identificar se seriam iguais ou diferentes, deste modo seria possivel observar até que ponto o tato poderia notar a diferença de vibrações, mesmo quando muito próximas. Neste experimento, o pesquisador aciona, no teclado, cada nota separadamente a fim de que o voluntário possa identificar as frequências de vibração. Foram utilizadas notas com grandes distâncias em tom ${ }^{10}$, até notas próximas com distância de semitom. Os pares utilizados foram:

\footnotetext{
${ }^{10}$ Tom é uma unidade de medida musical formada por dois semitons (menor intervalo audível para a música ocidental)
} 


\begin{tabular}{c|c|c|c}
\hline Notas & $\mathbf{H z}$ & rpm & Distância em tons \\
\hline $\mathbf{C}-\mathbf{A}$ & $66-111$ & $3.960-6.660$ & 4,5 \\
\hline $\mathbf{D}-\mathbf{D}$ & 74 & 4.008 & - \\
\hline $\mathbf{C}-\mathbf{E}$ & $66-83,1$ & $3.960-4.986$ & 2 \\
\hline $\mathbf{A}-\mathbf{B}$ & $111-124,6$ & $6.660-7.476$ & 1 \\
\hline $\mathbf{G}-\mathbf{G} \# \mathbf{~ / A b}$ & $98,8-104,7$ & $5.928-6.282$ & 0,5 \\
\hline $\mathbf{A}-\mathbf{A}$ & 111 & 6.660 & - \\
\hline
\end{tabular}

Tabela 2: Pares de vibrações para identificação. Fonte: Elaboração própria.

De acordo com sua distância em tons e semitons, estes pares de notas podem ser classificados da seguinte forma: C - A (sexta maior); D - D (uníssono); C - E (terça maior); A - B (segunda maior); G - G\#/Ab (segunda menor) e A - A (uníssono).

Terminada a primeira seção de identificação de frequências, os voluntários seguiram para a segunda etapa, que consistiu na identificação e reprodução de padrões rítmicos. Nesta etapa, uma nota aleatória do teclado foi utilizada para realizar um padrão de ritmo, cabendo ao indivíduo apenas perceber e reproduzir este ritmo batendo, com a mão livre, em uma superfície próxima. Deste modo, ficou a cargo do pesquisador analisar a fidelidade da repetição emitida pelo voluntário. Os padrões executados foram os seguintes:

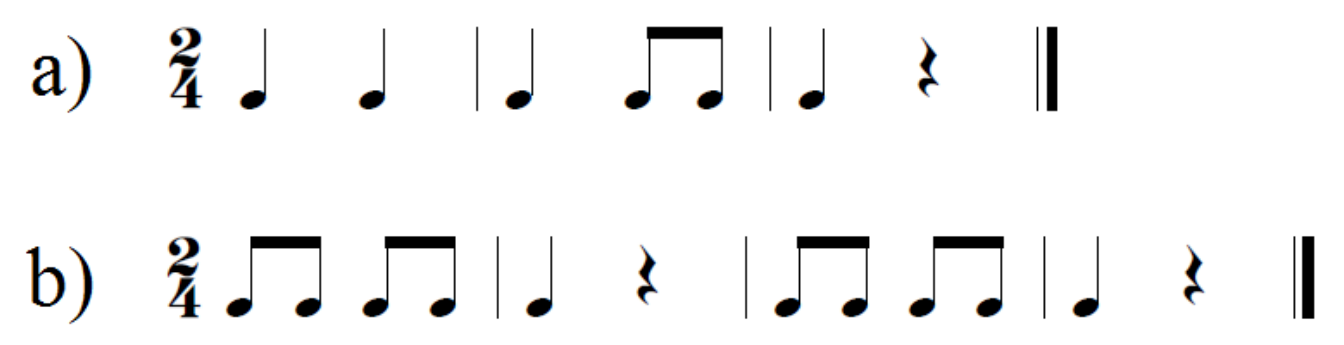

Figura 6: Padrões de percepção rítmica para reprodução. Fonte: Elaboração própria.

Os aspectos abordados nesta parte do experimento foram de fundamental importância para analisar as facilidades de percepção rítmica dos indivíduos, assim como as dificuldades em comum aos dois grupos expostos aos testes.

\section{Os testes com músicos}

Nesta etapa do experimento, os exercícios foram conduzidos a fim de testar a capacidade de percepção dos indivíduos ouvintes com treinamento musical. Além de diferenciar vibrações (entre baixa ou alta), os mesmos precisaram identificar padrões rítmicos e melódicos (com identificação de 
notas). Ao questionário aplicado a estes indivíduos, foram acrescentados alguns itens diferentes da etapa anterior.

A percepção dos padrões rítmicos se deu da seguinte forma: a) ao voluntário foi informada a fórmula de compasso ${ }^{11}$ escolhida para execução; b) após perceber a série de vibrações, o indivíduo deveria transcrevê-la utilizando as figuras rítmicas padrão.

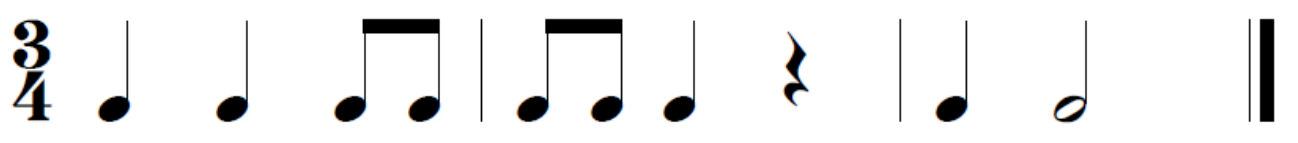

Figura 7: Padrões de percepção rítmica para transcrição.

Fonte: Elaboração própria.

Terminada a seção rítmica, foram apresentados (escritos em partitura) dois padrões melódicos de seis notas sucessivas, por item. O voluntário deveria sentir as notas da sequência, executada pelo pesquisador ao teclado da ferramenta, e indicar a qual padrão melódico impresso esta seria referente, como demonstrado na Figura 8 a seguir:
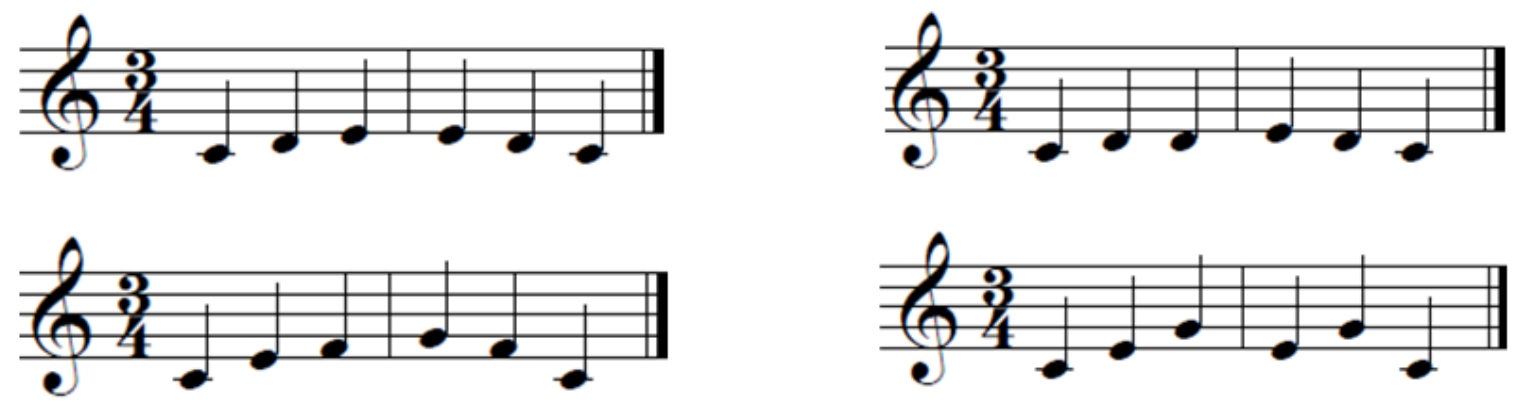

Figura 8: Padrões para percepção melódica tátil. Fonte: Elaboração própria.

Em cada um dos itens, uma nota de frequência próxima foi alterada a fim de observar a capacidade percepção tátil em trechos de conjuntos de notas.

Ao fim dos testes melódicos, foi executada a melodia (sem identificação) da música "Asa Branca", composta por Luiz Gonzaga (1912-1989) e Humberto Teixeira (1915-1979), cabendo ao individuo tal reconhecimento.

\section{RESULTADOS}

Com o objetivo de auxiliar a acessibilidade dos surdos ao ensino formal de música, analisar os métodos de ensino para esta comunidade e compreender as relações entre os sentidos (audição e tato), os dados

\footnotetext{
${ }^{11}$ Fórmula de compasso se refere à fração indicada no início de cada partitura, indicando as relações de duração das figuras rítmicas.
} 
descritos nesta pesquisa podem corroborar a hipótese da possibilidade de tradução das notas musicais em vibrações táteis. Considerando a capacidade da percepção dos indivíduos, por meio da ferramenta aqui proposta, podemos colaborar com estudos futuros acerca do tema.

Resultados do questionário com indivíduos surdos e ouvintes não músicos

As frequências expostas neste exercício aos indivíduos são as mesmas descritas anteriormente na Tabela 2. Contendo intervalos que partem do uníssono (mesma nota) até uma sexta maior (4 tons e meio de distância entre as notas), estes pares de notas permitem verificar até que ponto é possivel identificar a variação de vibrações da ferramenta, tendo como menor intervalo o semitom.

Foi possivel observar que os individuos ouvintes obtiveram um percentual de 5,3\% a mais de acertos quanto aos indivíduos surdos, nas distinções das vibrações. A dificuldade de distinção de frequências próximas, a exemplo dos intervalos de segunda maior (1 tom de distância entre as notas) e segunda menor (meio tom entre as notas), esteve presente nos dois grupos de voluntários nesta etapa. Este resultado corrobora o pensamento de Sekeff (2007), que descreve que a percepção musical se trata de um processo de aprimoramento do indivíduo, e apenas com o treinamento poderá ocorrer mais sensibilidade para a percepção das vibrações. Serão descritos, a seguir, os percentuais de cada grupo.

\begin{tabular}{c|c|c}
\hline Notas & $\begin{array}{c}\text { Percentual de acertos } \\
\text { dos } \\
\text { ouvintes }\end{array}$ & $\begin{array}{c}\text { Percentual de acertos } \\
\text { dos surdos }\end{array}$ \\
\hline $\mathbf{C}-\mathbf{A}$ & $100 \%$ & $100 \%$ \\
\hline $\mathbf{D}-\mathbf{D}$ & $100 \%$ & $100 \%$ \\
\hline $\mathbf{C}-\mathbf{E}$ & $100 \%$ & $100 \%$ \\
\hline $\mathbf{A}-\mathbf{B}$ & $50 \%$ & $14,2 \%$ \\
\hline $\mathbf{G}-\mathbf{G \#}$ /Ab & $50 \%$ & $28,5 \%$ \\
\hline $\mathbf{A}-\mathbf{A}$ & $75 \%$ & $100 \%$ \\
\hline TOTAL & $\mathbf{7 9} \%$ & $\mathbf{7 3 , 7} \%$ \\
\hline
\end{tabular}

Tabela 3: Resultado sobre a distinção entre as vibrações para surdos e não músicos. Fonte: Elaboração própria.

Posteriormente, um exercício de percepção rítmica (Figura 10) foi apresentado aos voluntários, sendo solicitado que os mesmos o reproduzissem. Neste experimento foi notada uma facilidade maior de resposta por parte dos indivíduos. Tal fato pode ser explicado devido à 
capacidade de interpretação rítmica ser algo intrínseco ao corpo humano. Para Nobre et al. (2011), o ritmo interno do nosso corpo, como batimentos cardíacos, pressão arterial ou até mesmo sinapses cerebrais, auxilia no modo como percebemos as estruturas da música. A sensação emocional que o ritmo musical provoca advém do sistema motor, este sendo o primeiro sistema a se desenvolver, antes mesmo do sistema sensorial. Em relação à prática musical, o ritmo opera dentro da duração e do tempo já propostos pela própria música, induzindo, assim, uma ordem coerente nas respostas do comportamento motor do sistema nervoso do indivíduo (Sekeff, 2007).

Como este quesito foi de cunho prático, uma análise de porcentagem de acerto de cada indivíduo foi realizada. Os itens a e b, descritos na Figura 6, foram executados para os individuos, gerando um resultado total por grupo, como demonstrado na Tabela 4.

\begin{tabular}{c|c|c}
\hline Exercicio & $\begin{array}{c}\text { Percentual de acertos dos } \\
\text { ouvintes }\end{array}$ & $\begin{array}{c}\text { Percentual de acertos dos } \\
\text { surdos }\end{array}$ \\
\hline $\begin{array}{c}\text { Item a } \\
\text { (Especificar }\end{array}$ & $100 \%$ & $97,1 \%$ \\
\hline Item b & $100 \%$ & $84,2 \%$ \\
\hline TOTAL & $\mathbf{1 0 0} \%$ & $\mathbf{9 0 , 6 \%}$ \\
\hline
\end{tabular}

Tabela 4: Resultado da reprodução de padrões rítmicos. Fonte: Elaboração própria.

Aos individuos que tiveram dificuldades na identificação dos ritmos, foram apresentados alguns exercícios extras, mais simples, sendo possivel notar que os mesmos possuíam naturalmente uma dificuldade de compreensão deste elemento musical. Miguel (2012) descreve que a passagem do tempo é percebida pela ação conjunta dos gânglios da base, área motora suplementar, cerebelo e córtex pré-frontal, as mesmas áreas neurais responsáveis pela coordenação de movimentos. Deste modo, na medida em que tempo e ritmo são conceitos indissociáveis, a percepção rítmica está integrada à percepção temporal.

\section{Resultados do questionário com indivíduos músicos}

Aos músicos, o primeiro exercício apresentado foi igual ao do grupo anterior, demonstrado na Tabela 2, a fim de comparar se o treinamento musical prévio os auxiliaria também na percepção tátil. Para Linda Davidoff (2007), o treinamento auditivo/musical é um processo de organizar e interpretar dados sensoriais recebidos para desenvolver a consciência do ambiente que nos cerca, atribuindo significado a estes.

Os individuos obtiveram um número maior de acertos em relação ao grupo sem conhecimento musical. Os erros na distinção das notas emitidas, em sua maioria, ocorreram nas frequências mais próximas, assim como ocorreram nos grupos anteriores. Estas, por possuírem os ciclos de 
repetições $(\mathrm{Hz})$ quase iguais, a exemplo das notas Mi e Fá, respectivamente $83,1 \mathrm{~Hz}$ e $85,1 \mathrm{~Hz}$, tornam-se de difícil compreensão para o indivíduo, mesmo que este possua treinamento auditivo.

$O$ resultado pode ser representado na tabela a seguir.

\begin{tabular}{c|c}
\hline Notas & $\begin{array}{c}\text { Percentual de acertos dos } \\
\text { músicos }\end{array}$ \\
\hline C - A & $100 \%$ \\
\hline D - D & $66,6 \%$ \\
\hline $\mathbf{C}-\mathbf{E}$ & $100 \%$ \\
\hline $\mathbf{A}-\mathbf{B}$ & $66.6 \%$ \\
\hline $\mathbf{G}-\mathbf{G \# / A b}$ & $66.6 \%$ \\
\hline $\mathbf{A}-\mathbf{A}$ & $100 \%$ \\
\hline TOTAL & $\mathbf{8 3 , 3} \%$ \\
\hline
\end{tabular}

Tabela 5: Resultado sobre a distinção entre as vibrações para músicos. Fonte: Elaboração própria.

O quesito referente à transcrição do ditado rítmico, descrito na Figura 11 , obteve $100 \%$ de reconhecimento por parte dos indivíduos. Além de testar a capacidade de reconhecimento rítmico, este exercício foi proposto também para certificar a eficácia da ferramenta quanto à sua latência. Deste modo, podemos constatar que o tempo de resposta entre o teclado e o motor é praticamente imperceptivel, tornando possivel a reprodução das figuras de valores musicais com exatidão.

A Figura 12 representa o exercício para identificação de padrões melódicos. Neste também houve $100 \%$ de acerto. Mesmo contendo, em uma das alternativas, uma nota de frequência próxima que não correspondia ao tocado, os indivíduos conseguiram identificar qual alternativa era a correta, em alguns dos casos até mesmo cantarolando o que haviam sentido nas vibrações.

Para finalizar os exercícios, ainda na temática de reconhecimento melódico nas vibrações, foi tocada a música "Asa branca" para reconhecimento. Neste tópico, o percentual de acertos por parte dos indivíduos foi de $66,6 \%$. Em busca de entender o porquê do não reconhecimento, por parte de um dos individuos, visto que as notas e ritmos foram, aparentemente, claros para os outros, o trecho apresentado foi tocado em um teclado convencional (com sons), porém, mesmo assim, o indivíduo não o reconheceu. Isso demonstra que a percepção, além de treinamento, requer conhecimentos e experiências anteriores por parte do indivíduo. 


\section{CONCLUSÃO}

Ao analisar os resultados obtidos nas subsessões anteriores, pode-se concluir que a ferramenta conseguiu desempenhar a função para a qual foi desenvolvida, tal como um instrumento musical convencional.

A latência, entre o acionamento dos botões e a resposta do motor, não foi algo perceptivel aos indivíduos participantes, tornando possivel a percepção e reprodução das figuras de valores musicais. O desempenho do motor vibracall, em relação às frequências propostas, ocorreu de forma aceitável, possibilitando a inteligibilidade das notas, mesmo quando próximas. Para estudos futuros, há a possibilidade de teste com motores de maior capacidade de rotação, o que permitirá o alcance de notas com frequências mais altas.

O desempenho dos voluntários participantes foi satisfatório e animador em relação à utilização da ferramenta, sendo importante aqui citar uma frase que foi comum a dois indivíduos, um surdo e um ouvinte sem treinamento: "É interessante porque podemos sentir como é a diferença das notas". Segundo Edwards (1974), o que torna significativa uma experiência musical para o aluno surdo é a possibilidade que ele tem de construir o conhecimento musical a partir dos conceitos musicais, ou seja, "[...] se a finalidade de ensinar a música ao surdo for fazê-lo aprender algo sobre a música, então se deve ensinar música a ele" (Edwards, 1974, p.100). Deste modo, ao despertar o interesse acerca do ensino musical em indivíduos da comunidade surda, a ferramenta desenvolvida cumpriu parte do seu objetivo.

O resultado sobre a distinção de frequências mostrou que é possivel interpretá-las através do tato, mesmo quando muito próximas; deste modo, fazendo uso de um estudo frequente de percepção, o indivíduo poderá atingir a compreensão musical desejada. Para Fonterrada (2005), a percepção musical não trata apenas do "ouvir", ela está relacionada à captação de um som e em seguida lhe atribuir um significado. Sendo assim, cabe ao indivíduo realizar estudos sistemáticos, com exercícios rítmicos e melódicos, a fim de ampliar sua capacidade de interpretação.

A representação rítmica se mostrou eficaz para ambos os grupos, tornando maior o îndice de acertos em sua identificação e reprodução, até mesmo para os indivíduos surdos, que em sua maioria não haviam tido contato anterior com os elementos da música. Tal parâmetro pode auxiliar os indivíduos surdos no estudo prático em instrumentos percussivos.

Para futuras utilizações da ferramenta, algumas modificações ergonômicas e de hardware podem ser aplicadas, a fim de torná-la mais versátil. A ampliação das frequências (notas) disponíveis pode ser realizada, permitindo ao indivíduo, até mesmo, interpretar repertórios que estejam inseridos na extensão da ferramenta. Deste modo, sugerem-se novos 
estudos acerca da capacidade de percepção tátil dos indivíduos surdos, buscando compreender os limites de vibrações que eles podem identificar.

\section{REFERENCIAS}

ARAÚJO, Felipe A.; BATISTA, Carlos E. C.F. Auris: System for Facilitating the Musical Perception for the Hearing Impaired. In: SIMPÓSIO BRASILEIRO DE MULTIMÍDIA E WEB - WEBMEDIA, 22., 2016, Teresina. Anais [...]. Teresina: SBC, 2016.

ARAÚJO, F. A.; BRASIL, F. L.; SANTOS, A. C. L.; JUNIOR, L. S. B.; DUTRA, S. P. F.; BATISTA, C. E. C. F. Auris System: Providing Vibrotactile Feedback for Hearing Impaired Population. BioMed Research International, v. 2017, 2017.

BARRETO, Sidirley de J.; CHIARELLI, Lígia K. M. A importância da musicalização na educação infantil e no ensino fundamental: a música como meio de desenvolver a inteligência e a integração do ser. Recre@rte, n. 3, jun. 2005. Disponível em:

http://www.iacat.com/revista/recrearte/recrearte03/musicoterapia.htm. Acesso em: 15 abr. 2016.

BEAR, M. F.; CONNORS, Barry W.; PARADISO, Michael A. Neurociências: desvendando o sistema nervoso. 3. ed. Porto Alegre: Artmed, 2010.

BRÉSCIA, Vera Lucia Pessagno. Educação musical: bases psicológicas e ação preventiva. Campinas: Átomo, 2003.

CERVELLINI, Nadir H. A musicalidade do surdo, representação e estigma. São Paulo: Plexus, 2003.

CERVO, Amado Luiz; BERVIAN, Pedro Alcino. Metodologia científica. 5. ed. São Paulo: Prentice Hall, 2002.

CRUZ, A. L. de C. Music for the deaf: a qualitative approach. In: LABBO, L. D.; FIELD, S. L. (Eds.). Conference Proceedings of the Qualitative Interest Group. 1997. Acesso em: 23 abr. 2016.

DALCROZE, Emile J. Le Rythme, La musique et l'éducation. Paris: Jobin e Cie, 1920.

DARROW, A. A. Music for deaf. Music Educators Journal, v. 71, n. 6, p. 3335, 1985.

DAVIDOFF, Linda L. Introdução à Psicologia. 30. ed. São Paulo: Makron Books, 2001.

DEL BIANCO, Silvia. Jacques-Dalcroze. In: DIAZ, M.; GIRÁLDEZ, A. (Coords.). Aportaciones teóricas y metodológicas a La educación musical: uma 
selección de autores relevantes. Espanha: GRAÓ, Biblioteca de Eufonia, 2007. p. 23-32. Serie Didáctica de La expressión musical.

EDWARDS, Eleanor M. Music Education for the Deaf. Journal of Music Therapy, v. 13, oct. 1976.

FAHEY J. D.; BIRKENSHAW, L. Education of the deaf bypassing the ear: the perception of music by feeling and touch. Music Educators Journal, v. 58, p. 44-49, 1972.

FINCK, Regina. Ensinando música ao aluno surdo: perspectivas a ação pedagógica inclusiva. Tese (Doutorado) - Universidade Federal do Rio Grande do Sul, Porto Alegre, 2009.

FONTERRADA, Marisa. De tramas $e$ fios: um ensaio sobre música e educação. São Paulo: Editora da UNESP, 2005.

GAINZA, Violeta H. Estudos de Psicopedagogia Musical. 3. ed. São Paulo: Summus, 1988.

GARRIDO, A. A. G.; STOVEL, V. D. R.; VELÁZQUEZ, F. R. G.; PÉREZ, H. V.; VÁZQUEZ, R. R.; VALDEZ, A. E.; CAMPOS, L. R. Vibrotactile Discrimination Training Affects Brain Connectivity in Profoundly Deaf Individuals. Frontiers in human neuroscience, 11:28, 2017.

GIL, A. C. Como elaborar projetos de pesquisa. 4. ed. São Paulo: Atlas, 2007.

GROUT, Donald V.; PALISCA, Claude V. História da música ocidental. Trad. Ana Luiza Maria. Lisboa: Gradiva, 2007.

HOHMANN, M.; WEIKART, D. Educar a criança. Lisboa: Fundação Calouste Gulbenkian, 1997.

IBANEZ, César Augusto. O som, seus parâmetros, e a música: o ensino dos elementos musicais. Dissertação (Mestrado em Educação) - Universidade Estadual de Londrina, Paraná, 2010.

JOURDAIN, R. Música, cérebro e êxtase: como a música captura nossa imaginação. Rio de Janeiro: Objetiva, 1998.

KOELLREUTTER, Hans J. Cadernos de estudo: educação musical. São Paulo, n. 6, p. 1-210, 1998.

MAGALHÃES, Liana Arduino de. O desenvolvimento musical e a interação de alunos surdos em uma escola regular de ensino: um estudo de caso. Rio de Janeiro, 2014. Dissertação (Mestrado em música) - Centro de Letras e Artes, Universidade Federal do Rio de Janeiro, Rio de Janeiro, 2014.

MALHOTRA, N. Pesquisa de marketing. 3. ed. Porto Alegre: Bookman, 2001. 
MELO, A. M. Acessibilidade e inclusão digital em contexto educacional. In: NUNES, M. A. S. N.; ROCHA, E. M. Anais da III Jornada de Atualização em Informática na Educação. Dourados: UFGD, 2014. p. 1-41.

MENEZES, Flo. A acústica musical em palauras e sons. Cotia: Ateliê Editorial, 2003.

MIGUEL, M. A. L. Estimativa de tempo em humanos: bases, ontogênese e variação diária. Revista da Biologia, v. 9, n. 3, p. 74-79, 2012.

NASCIMENTO, Leonardo Penteado. Desenvolvimento do teste de sensibilidade tátil da mão. Dissertação (Mestrado em Ciência da Reabilitação) - Universidade de São Paulo, Paraná, 2014.

NOBRE, D. V.; LEITE, H. R.; ORSINI, M.; CORREA, C. L. Respostas fisiológicas ao estímulo musical: revisão de literatura. Revista Neurociências, Rio de Janeiro, 2012.

OLIVEIRA, L. C.; GOLDENBERG, R.; MANZOLLI, J. Percepção de instrumento musical sintético construido por modelo experimental. In: SIMPÓSIO DE 131 COGNIÇÃO E ARTES MUSICAIS - SIMCAM, 4., 2008, São Paulo. Anais [...]. São Paulo: SIMCAM, 2008. Disponivel em: http://www.abcogmus.org/documents/SIMCAM4.pdf. Acesso em: 9 jun. 2018.

PRIOLLI, Maria Luisa de Mattos. Principios básicos da música para a juventude. Rio de Janeiro: Casa Oliveira de Músicas, 1986.

RICHARDSON, R. J. Pesquisa social: métodos e técnicas. 3. ed. São Paulo: Atlas, 1999.

RODRIGUES, Felipe Viegas. Fisiologia sensorial. Revista da Biologia, São Paulo, 2010.

SANTOS, Rocilene Otaviano dos. Estrutura e Funções do Córtex Cerebral. Monografia (Licenciatura em Ciências Biológicas) - Centro Universitário de Brasília, Brasília, 2002.

SEKEFF, Maria de Lourdes. Da música: seus usos e recursos. 2. ed. São Paulo: Editora Unesp, 2007.

VIANA, Regina Lúcia. A integração do surdo: uma abordagem multissensorial. Rio de Janeiro: CELD, 1996.

WECKER, Karl. Music for totally deaf children. Music Educators Journal, v. 6, p. 45-47, 1939. 
Caio Vinícius Pereira de Sá é Graduado em Produção Musical pela Universidade Federal de Campina Grande, especialista em Educação Musical pela Universidade Candido Mendes e mestre em Arte Computacional pela Universidade Federal de Campina Grande. https://orcid.org/0000-0001-8659-4708

Carlos Eduardo Coelho Freire Batista é Doutor em Informática pela Pontifícia Universidade Católica do Rio de Janeiro (PUC-Rio, 2013). Possui Graduação em Ciências da Computação pela Universidade Federal da Paraíba (2004) e Mestrado em Informática pela Universidade Federal da Paraíba (2008), sendo membro do Laboratório de Aplicações de Vídeo Digital (LAViD) desde 2003. Realizou pós-doutorado na University of California (San Diego, 2017), trabalhando na área de computação musical. Atualmente é professor adjunto do Centro de Informática da Universidade Federal da Paraíba, membro permanente do Programa de PósGraduação em Computação, Comunicação e Artes. É pesquisador colaborador do Laboratório Telemídia da PUC-Rio e coautor das especificações do middleware Ginga, participando do Grupo de Trabalho de Middleware do Fórum Brasileiro de TV Digital e também atuando no processo de padronização internacional das tecnologias relacionadas junto à União Internacional de Telecomunicações (UIT). Tem experiência na área de Ciência da Computação, com ênfase em sistemas multimídia, atuando principalmente nos seguintes temas: sistemas multimídia distribuídos, TV digital interativa, vídeo e áudio digital e música computadorizada. https://orcid.org/0000-0002-2593-9052

Donately da Costa Santos possui ensino médio pela Escola Técnica Redentorista (2005). Atualmente é técnico em Eletricidade da Universidade Federal de Campina Grande. Tem experiência na área de Engenharia Elétrica. https://orcid.org/0000-0002-9724-2027 